\title{
Article
}

\section{Deep Oxidation of Methanol Using a Novel Pt/Boron Nitride Catalyst}

\author{
Jeffrey C. S. Wu, Ya-Chun Fan, and Chih-An Lin
}

Ind. Eng. Chem. Res., 2003, 42 (14), 3225-3229 • DOI: 10.1021/ie020880I

Downloaded from http://pubs.acs.org on November 28, 2008

\section{More About This Article}

Additional resources and features associated with this article are available within the HTML version:

- $\quad$ Supporting Information

- $\quad$ Links to the 2 articles that cite this article, as of the time of this article download

- $\quad$ Access to high resolution figures

- $\quad$ Links to articles and content related to this article

- $\quad$ Copyright permission to reproduce figures and/or text from this article

\section{View the Full Text HTML}

\section{ACS Publications}




\title{
Deep Oxidation of Methanol Using a Novel Pt/Boron Nitride Catalyst
}

\author{
J effrey C. S. Wu,* Ya-Chun Fan, and Chih-An Lin \\ Department of Chemical Engineering, National Taiwan University, Taipei, Taiwan 10617, R.O.C.
}

\begin{abstract}
Deep oxidation of methanol was conducted using a novel Pt/BN catalyst in a steady-state-flow reactor. Hexagonal boron nitride (BN) is a graphitelike material in powder form with a specific surface area of $49 \mathrm{~m}^{2} / \mathrm{g}$. A catalyst with $0.37 \mathrm{wt} \% \mathrm{Pt}$ was prepared by the incipient wetness method using $\mathrm{H}_{2} \mathrm{PtCl}_{6}$ as a precursor dissolved in methanol. The reaction temperature ranged from -10 to $200^{\circ} \mathrm{C}$. The concentration of methanol varied from 1000 to 4000 ppmv, while the oxygen varied from 5 to $80 \%$ and was balanced with nitrogen. The vol ume hourly space vel ocity was approximately $50000 \mathrm{~h}^{-1}$. Experimental results showed that a $50 \%$ methanol conversion could be achieved at room temperature $\left(20^{\circ} \mathrm{C}\right)$, reaching $95 \%$ conversion at $75{ }^{\circ} \mathrm{C}$, while Pt/ $\mathrm{Al}_{2} \mathrm{O}_{3}$, Dash 220 (a commercial Pt/alumina catalyst), and $\mathrm{PtPd} / \mathrm{CeO}_{2} / \mathrm{Al}_{2} \mathrm{O}_{3}$ catalysts required considerably higher temperatures under the same conditions. The high oxidation activity of Pt/ $\mathrm{BN}$ was attributed to the weak $\mathrm{Pt}-\mathrm{O}$ bonding of the Pt clusters on the BN surface, which led to high oxidizing reactivity. Regression analysis revealed that the reaction order of methanol was 1 , while that of oxygen was -0.6 . A mechanism of the Langmuir-Hinshelwood model was established based on the experimental results. Kinetic analysis suggested that the methanol adsorption on Pt would be the rate-limiting step on the Pt/BN catalyst.
\end{abstract}

\section{Introduction}

Materials traditionally used as supports are insulating oxides such as $\mathrm{SiO}_{2}, \gamma-\mathrm{Al}_{2} \mathrm{O}_{3}$, silica-alumina, and various zeolites. ${ }^{1}$ These oxides possess low thermal conductivity, causing sintering of the supported metal on hot spots, numerous acidic and basic sites, and the coverage of the catalyst with water at low temperature due to its hydrophilic surface. The graphitelike hexagonal boron nitride (BN) is the most stable isomer of $\mathrm{BN}$ under ambient conditions. ${ }^{2}$ BN has high thermal conductivity, temperature stability, acid-base resistance, and appropriate chemical inertness. Furthermore, BN is hydrophobic, thus preventing moisture condensation on its surface.

Our laboratory recently investigated Pt catalysts supported on hexagonal $\mathrm{BN} .3,4$ The Pt/BN catalysts were compared with $\mathrm{Pt} / \gamma-\mathrm{Al}_{2} \mathrm{O}_{3}$ for the deep oxidation of gasoline vapor. The oxidative conversion of gasoline vapor rose to $90 \%$ at approximately $150{ }^{\circ} \mathrm{C}$. In contrast, the light-off temperature (for $50 \%$ conversion) of $\mathrm{Pt} /$ $\gamma-\mathrm{Al}_{2} \mathrm{O}_{3}$ with the same pretreatment was at $250^{\circ} \mathrm{C}$. The $\mathrm{Pt} / \mathrm{BN}$ catalyst remains active for $80 \mathrm{~h}$, meanwhile the activity of $\mathrm{Pt} / \gamma-\mathrm{Al}_{2} \mathrm{O}_{3}$ declined continuously with time when the temperature was fixed at $185^{\circ} \mathrm{C} .{ }^{3}$ The $\mathrm{BN}$ surface bonds more weakly to Pt particles than does $\gamma-\mathrm{Al}_{2} \mathrm{O}_{3}$, indicating a weaker interaction between the Pt and the support. This weaker bonding between the support and the Pt particles allows the particles to remain in a reduced state more easily. The reduced state of Pt particles on Pt/BN causes a weaker $\mathrm{Pt}-\mathrm{O}$ bond on the surface of $\mathrm{Pt}$ to supply more reactive oxygen atoms and thus promote catalytic oxidation. ${ }^{4}$ Previous works have concluded that Pt/BN outperforms the traditional oxide-supported Pt catalysts in life and activity.

* To whom correspondence should be addressed. Tel.: +8862-23631994. Fax: +886-2-23623040. E-mail: cswu@ntu.edu.tw.
Methanol is an alternative fuel for internal combustion engines, with the potential simultaneously to increase the octane number and reduce air pollution. However, unburned methanol vapor released from vehicle exhaust pipes is a health hazard. Owing to the low temperature in methanol-fuel internal-combustion engines, a catalyst that is active under low temperature is extremely important, particularly when the operating temperature is lower than the dew point of exhaust gas in the catalytic converter. This study demonstrates the deep oxidation of methanol at extremely low temperature using a novel Pt/BN catalyst.

\section{Experimental Section}

(a) Catalysts. The hexagonal BN powder was purchased from High Performance Material Inc., Taiwan. $\gamma$-Alumina $\left(\gamma-\mathrm{Al}_{2} \mathrm{O}_{3}\right)$, a commonly used support, from Merck (St. Louis, MO) was used to prepare Pt $/ \gamma-\mathrm{Al}_{2} \mathrm{O}_{3}$ catalyst. The average particle diameters of the $\mathrm{BN}$ and $\gamma-\mathrm{Al}_{2} \mathrm{O}_{3}$ supports were 10 and $180 \mu \mathrm{m}$, respectively. Two commercial catalysts were used for comparison. A volatile organic compound (VOC) catalyst, $\mathrm{PtPd} / \mathrm{CeO}_{2} /$ $\mathrm{Al}_{2} \mathrm{O}_{3}$, was obtained from $\mathrm{KJ}$ Environmental Technology Co. (Taiwan). The total Pt and Pd loading of PtPd/CeO / $\mathrm{Al}_{2} \mathrm{O}_{3}$ is around 1 wt $\%$, being used as supplied by the manufacturer. Another combustion catalyst, Dash 220, was purchased from N. E. Chemcat Corp. (Tokyo, J apan). Dash 220 is an alumina-supported Pt catalyst with a specific surface area of $150 \mathrm{~m}^{2} / \mathrm{g}$ and was used as supplied by the manufacturer.

Platinum catalysts with 0.37 wt \% loading were prepared by the incipient-wetness method. The precursor salt, $\mathrm{H}_{2} \mathrm{PtCl}_{6} \cdot 6 \mathrm{H}_{2} \mathrm{O}$, which contained approximately 40 wt $\%$ platinum, was purchased from Acros Organics (Geel, Belgium). Methanol was found to be an effective solvent that could soak BN and dissolve the precursor salt. The catalysts were reduced in a flow of $30 \mathrm{~mL} / \mathrm{min}$ of a $20 \% \mathrm{H}_{2} / \mathrm{N}_{2}$ mixture at $300{ }^{\circ} \mathrm{C}$ for $2 \mathrm{~h}$, with the 


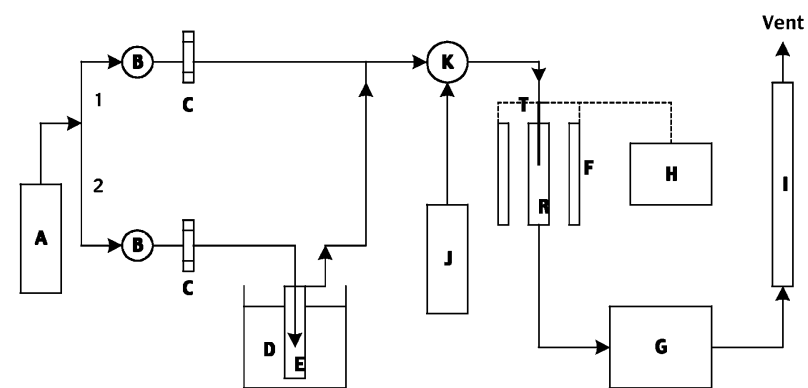

Figure 1. Schematic of the reactor system (A, air cylinder; $B$, pressure gauge; $C$, rotameter; $D$, water bath; $E$, methanol saturator; $\mathrm{F}$, furnace; $\mathrm{G}$, gas chromatograph; $\mathrm{H}$, furnace controller; I, bubble meter; J , pretreatment gas; K, six-way valve; R, reactor; $\mathrm{T}$, thermocouple).

temperature being increased from room temperature to $300^{\circ} \mathrm{C}$ at $10^{\circ} \mathrm{C} / \mathrm{min}$, then cool ed to room temperature, and stored in a desiccator for later use. The specific surface areas of the catalysts were measured by $\mathrm{N}_{2}$ adsorption, using the Brunauer-E mmett-Teller equation. The detailed characteristics of Pt/BN catalysts have been described elsewhere. ${ }^{4}$

The acidity of $\mathrm{BN}$ and $\mathrm{Al}_{2} \mathrm{O}_{3}$ supports was studied using the temperature-programmed desorption (TPD) of pyridine. Fresh support $(0.2 \mathrm{~g})$ was pretreated under a nitrogen flow at $400{ }^{\circ} \mathrm{C}$ for $1 \mathrm{~h}$ to remove adsorbed impurities and then cooled to near $50{ }^{\circ} \mathrm{C}$. Following saturation with pyridine vapor carried out by a nitrogen stream for $30 \mathrm{~min}$, the support was purged with Ar flow, and then the temperature was raised to $600{ }^{\circ} \mathrm{C}$ at 10 ${ }^{\circ} \mathrm{C} / \mathrm{min}$.

(b) Catalytic Oxidation. Figure 1 schematically illustrates the reaction system. $\mathrm{An} \mathrm{O}_{2} / \mathrm{N}_{2}$ stream through a methanol saturator was mixed with another $\mathrm{O}_{2} / \mathrm{N}_{2}$ stream. The concentration of methanol in the feed was regulated in the range 1000-4000 ppmv by adjusting the saturator temperature. Three gas cylinders provided three oxygen concentrations balanced with nitrogen, namely, 5, 20, and $80 \%$, respectively. The mixture passed through the reactor at $200 \mathrm{~mL} / \mathrm{min}$, representing a volume hourly space velocity of $50000 \mathrm{~h}^{-1}$. The catalyst $(0.3 \mathrm{~g})$ was charged in the middle of a straighttube Pyrex reactor with a $16 \mathrm{~mm}$ i.d. A thermocouple was placed in the center of the catalyst bed to record the reaction temperature and control the furnace. The reaction temperature varied from -10 to $200{ }^{\circ} \mathrm{C}$, and the subambient reaction temperature was maintained via chilled water circulation. The reactor was switched to a tubular furnace for temperatures above ambient temperature. The catalyst was heated $2 \mathrm{~h}$ at $300{ }^{\circ} \mathrm{C}$ under an air stream in the reactor and then cooled to room temperature before introducing methanol. All catalytic oxi dations were performed in the steady-state condition and started at a temperature that ensured zero conversion of the methanol. The concentration of methanol was measured at least two or three times in the steady state at each temperature using an online sampling loop in an HP GC6890. The thermal conductive and flaming ion detectors were connected in series so that hydrocarbon and non-hydrocarbon species could be measured simultaneously. Moreover, separation of $\mathrm{H}_{2} \mathrm{O}, \mathrm{CO}_{2}$, and most light hydrocarbons was accomplished using an HP-PLOT Q 30 m capillary column. Only water and carbon dioxide were detected in the methanol oxidation. Furthermore, the carbon balance was examined and found to be within a relative error of less than $10 \%$. The conversions of oxidation were
Table 1. Specific Area of Catalysts

\begin{tabular}{lcccc}
\hline & \multicolumn{4}{c}{ catalyst $\left(\mathrm{m}^{2} / \mathrm{g}\right)$} \\
\cline { 2 - 5 } & $\mathrm{Pt} / \mathrm{BN}$ & $\mathrm{Pt} / \mathrm{Al}_{2} \mathrm{O}_{3}$ & $\mathrm{PtPd} / \mathrm{CeO}_{2} / \mathrm{Al}_{2} \mathrm{O}_{3}$ & Dash 220 \\
\hline fresh & 48.5 & 112.9 & 102.3 & $150.0^{\mathrm{a}}$ \\
reactionb & 49.0 & 114.3 & 101.6 &
\end{tabular}

a Provided by N. E. Chemcat Corp. ${ }^{\text {b }}$ Methanol oxidation: total reaction time near $10 \mathrm{~h}, 30 \mathrm{~min}$ at maximum temperature, 140 ${ }^{\circ} \mathrm{C}$.

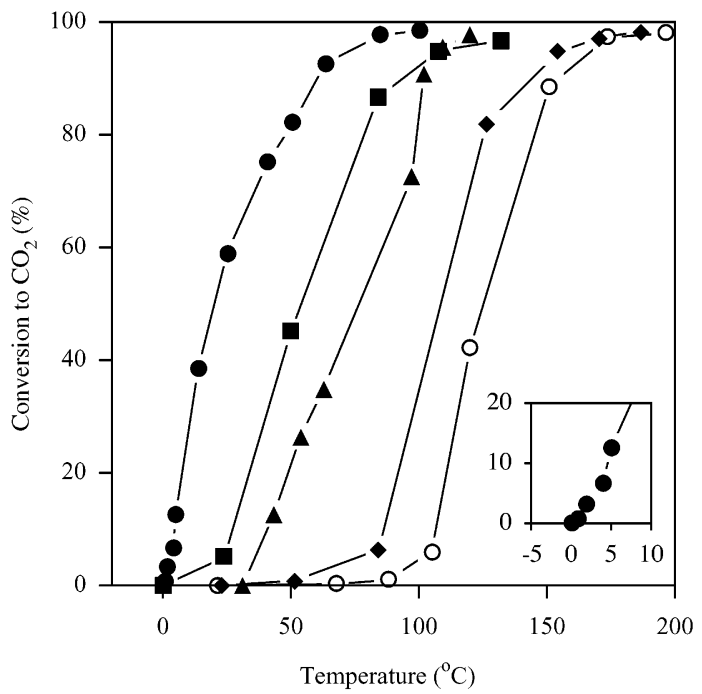

Figure 2. Oxidation of methanol using various catalysts (2000 ppmv, $20 \% \mathrm{O}_{2}$ ): •, Pt/BN; $\mathbf{\square}, \mathrm{PtPd} / \mathrm{CeO}_{2} / \mathrm{Al}_{2} \mathrm{O}_{3} ; \boldsymbol{\Delta}$, Dash 220 (N. E. Chemcat Corp.); $\diamond, \mathrm{Pt} / \mathrm{Al}_{2} \mathrm{O}_{3} ; \mathrm{O}, \mathrm{BN}$.

calculated based on the product, $\mathrm{CO}_{2}$. The reaction was also conducted under various flow rates to test the influence of mass-transfer resistance on the catalyst. No significant rate change was noted, meaning that the mass-transfer limitation was negligible.

\section{Results and Discussion}

Table 1 lists the specific surface areas of the catalysts. The Pt/BN has the lowest specific surface area among the four catalysts, at near $50 \mathrm{~m}^{2} / \mathrm{g}$. The specific surface areas of $\mathrm{Pt} / \mathrm{BN}, \mathrm{Pt} / \mathrm{Al}_{2} \mathrm{O}_{3}$, and $\mathrm{PtPd} / \mathrm{CeO}_{2} / \mathrm{Al}_{2} \mathrm{O}_{3}$ following the reaction with methanol at a maximum $140{ }^{\circ} \mathrm{C}$ closely resemble those of fresh catalysts. The Pt dispersion of the catalyst was measured by static hydrogen chemisorption. ${ }^{3,4}$ The $\mathrm{Pt} / \gamma-\mathrm{Al}_{2} \mathrm{O}_{3}$ catalyst shows a $\mathrm{Pt}$ dispersion of around $30 \%$. Meanwhile, the Pt/BN catalyst, with lower specific support surface areas, gives lower dispersions near $20 \%$.

Figure 2 presents the temperature dependencies of methanol oxidation to $\mathrm{CO}_{2}$ on Pt/BN, PtPd/CeO $/ \mathrm{Al}_{2} \mathrm{O}_{3}$, Dash 220, Pt $/ \gamma-\mathrm{Al}_{2} \mathrm{O}_{3}$, and blank support $\mathrm{BN}$, respectively. The pure BN support gives very extremely low activity, indicating that Pt is the primary active site in such an oxidation reaction. Conversions increase steeply with temperature in all catalysts. As shown in Figure 2 , the activity of Pt/BN was superior to that of PtPd/ $\mathrm{CeO}_{2} / \mathrm{Al}_{2} \mathrm{O}_{3}$, Dash 220, and $\mathrm{Pt} / \gamma-\mathrm{Al}_{2} \mathrm{O}_{3}$. Table 2 summarizes the light-off temperatures of the four catalysts. Generally, the light-off temperature of a VOC catalyst is defined as the temperature at which conversion reaches $50 \%$, assigned as $\mathrm{T}_{50}$. The lower $\mathrm{T}_{50}$, the higher the activity and the better the catalyst is. $\mathrm{T}_{50}$ of $\mathrm{Pt} / \mathrm{BN}$ was near $20{ }^{\circ} \mathrm{C}$, while those of $\mathrm{PtPd} / \mathrm{CeO}_{2} / \mathrm{Al}_{2} \mathrm{O}_{3}$, Dash 220 , and $\mathrm{Pt} / \gamma-\mathrm{Al}_{2} \mathrm{O}_{3}$ were approximately 55,75 , and 110 
Table 2. Light-Off Temperatures of Methanol Oxidation ${ }^{a}$

\begin{tabular}{lcc}
\hline \multicolumn{1}{c}{ catalyst } & $\mathrm{T}_{50}\left({ }^{\circ} \mathrm{C}\right)$ & $\mathrm{T}_{95}\left({ }^{\circ} \mathrm{C}\right)$ \\
\hline $\mathrm{Pt} / \mathrm{BN}$ & 20 & 75 \\
$\mathrm{PtPd} / \mathrm{CeO}_{2} / \mathrm{Al}_{2} \mathrm{O}_{3}$ & 55 & 110 \\
$\mathrm{Dash} 220_{\mathrm{Pt} / \mathrm{Al}_{2} \mathrm{O}_{3}}$ & 75 & 110 \\
& 110 & 155
\end{tabular}

a $\mathrm{T}_{50}\left({ }^{\circ} \mathrm{C}\right)$ : temperature at $50 \%$ conversion to $\mathrm{CO}_{2}$. $\mathrm{T}_{95}\left({ }^{\circ} \mathrm{C}\right)$ : temperature at $95 \%$ conversion to $\mathrm{CO}_{2}$.

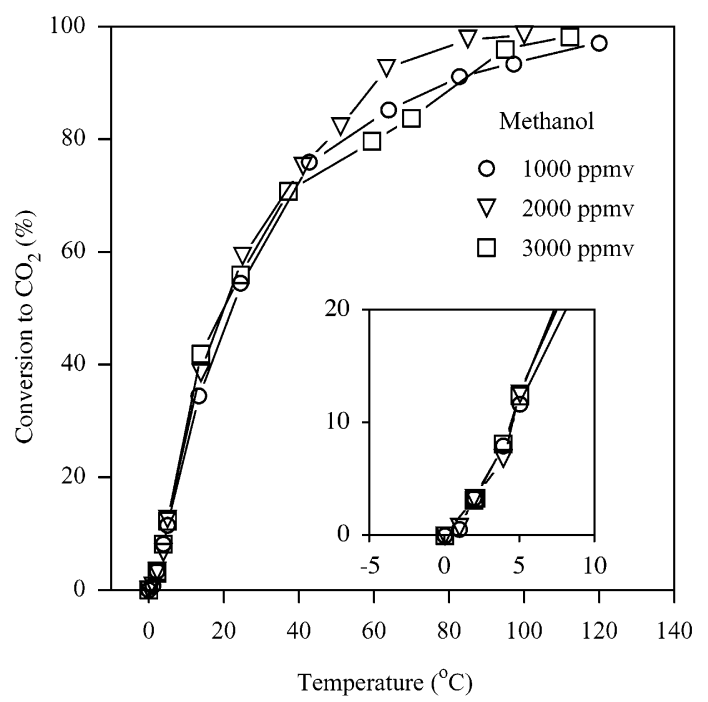

Figure 3. Effect of the methanol concentration in oxidation on a $\mathrm{Pt} / \mathrm{BN}$ catalyst $\left(20 \% \mathrm{O}_{2}\right)$.

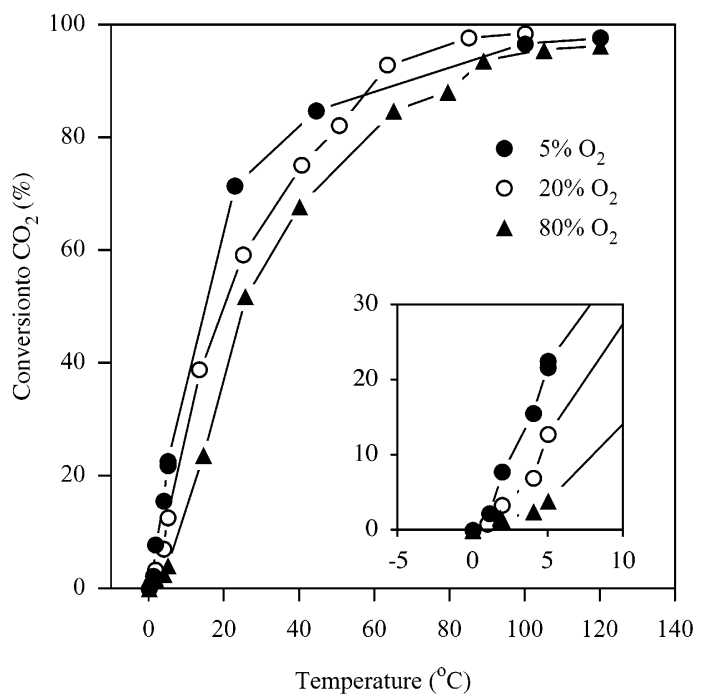

Figure 4. Effect of the $\mathrm{O}_{2}$ concentration in methanol oxidation on a Pt/BN catalyst (2000 ppmv methanol).

${ }^{\circ} \mathrm{C}$, respectively. N otably, methanol conversion reaches $95 \%$ at $\sim 75{ }^{\circ} \mathrm{C}$ on Pt/BN. However, temperatures exceeding $110^{\circ} \mathrm{C}$ are required to achieve $95 \%$ conversion on Dash 220 and $\mathrm{PtPd} / \mathrm{CeO}_{2} / \mathrm{Al}_{2} \mathrm{O}_{3}$.

Figures 3 and 4 show the concentration effects of methanol and oxygen on Pt/BN, respectively. Differences in the methanol concentration were observed to have only a minor influence on conversion. It may be that the range of methanol concentrations used in this study was too narrow to reveal the differences. Oxygen had a negative effect on the conversion under the experimental conditions. M ethanol conversion decreased with increasing oxygen concentration at the same temperature, especially at low conversion levels. The reason is that oxygen is more competitively adsorbed

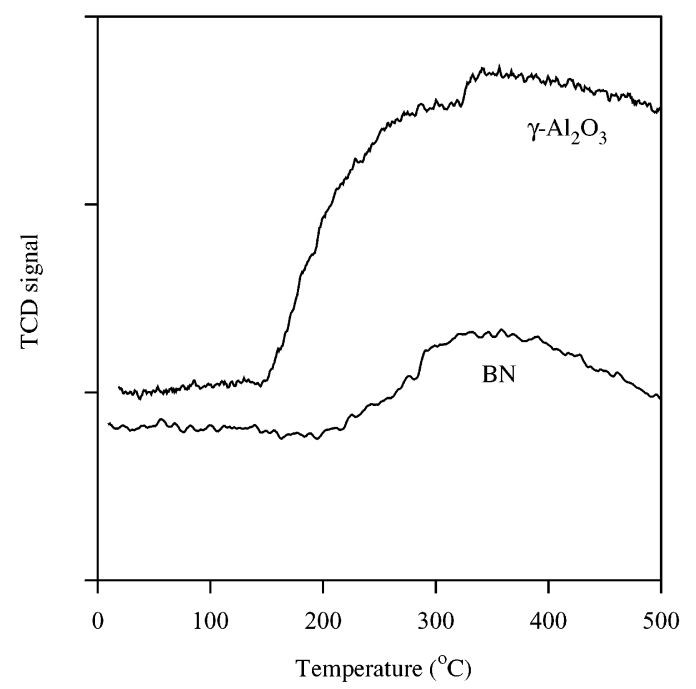

Figure 5. TPD of pyridine on supports.

on the active Pt sites than methanol. Thus, the number of active sites for methanol adsorption is insufficient, resulting in lowered methanol conversion at high oxygen concentrations.

Volter et al. ${ }^{5}$ and Aryafar and Zaera ${ }^{6}$ both conclude that hydrocarbon oxidation reactions over platinum occur on reduced sites more easily than on oxidized ones. The Pt particles on Pt/BN are more easily maintained in their reduced state, as was concluded in the previous characterization, a result that is believed to be the most important in causing the difference between the activities of $\mathrm{Pt} / \mathrm{BN}$ and $\mathrm{Pt} / \gamma-\mathrm{Al}_{2} \mathrm{O}_{3} .{ }^{4}$ Weaker bonding between $\mathrm{Pt}$ and ad-oxygen on $\mathrm{Pt} / \mathrm{BN}$ is thought to be responsible for supplying the more reactive surface oxygen atoms in the deep oxidation of methanol. Moreover, the low activity of $\mathrm{Pt} / \gamma-\mathrm{Al}_{2} \mathrm{O}_{3}$ is believed to result from the strong bonding between $\mathrm{Pt}$ and ad-oxygen and the presence of a more residual $\mathrm{PtO}_{x} \mathrm{Cl}_{y}$ complex on the surface of the support. Consequently, the ad-oxygen on the $\mathrm{Pt} / \mathrm{BN}$ is more reactive than that on $\mathrm{Pt} / \gamma-\mathrm{Al}_{2} \mathrm{O}_{3}$.

The acidity of the catalyst can be generally studied by TPD using a basic adsorbate. Figure 5 displays the TPD spectra of pyridine on $\mathrm{BN}$ and $\gamma-\mathrm{Al}_{2} \mathrm{O}_{3}$. The desorption peak of $\gamma-\mathrm{Al}_{2} \mathrm{O}_{3}$ is high and widespread, ranging from 150 to over $500{ }^{\circ} \mathrm{C}$, while that of $\mathrm{BN}$ is low and significantly narrower, ranging from 200 to near $500{ }^{\circ} \mathrm{C}$. The amount of pyridine adsorption indicates that the quantity of acidic sites of $\mathrm{BN}$ is significantly less than that of $\gamma-\mathrm{Al}_{2} \mathrm{O}_{3}$. The acidic strength of $\mathrm{BN}$ is also weaker than that of $\gamma-\mathrm{Al}_{2} \mathrm{O}_{3}$. Hinz et al. suggested that a basic support, such as $\mathrm{MgO}$, was more favorable than an acidic support (e.g., $\gamma-\mathrm{Al}_{2} \mathrm{O}_{3}$ ) in methanol oxidation using supported Pt catalysts. ${ }^{7}$ The acid-base character of the support is an important factor influencing the performance of supported Pt in methanol oxidation at low temperature. Therefore, $\mathrm{T}_{50}$ of $\mathrm{Pt} / \mathrm{BN}$ is considerably lower than that of $\mathrm{Pt} / \gamma-\mathrm{Al}_{2} \mathrm{O}_{3}$, despite the dispersion of Pt on BN (20\%) being lower than that on $\gamma-\mathrm{Al}_{2} \mathrm{O}_{3}(30 \%)$.

Our previous work found a slight decrease in the Pt dispersion following aromatics oxidation at high temperatures $\left(>300{ }^{\circ} \mathrm{C}\right)$ on Pt/BN. ${ }^{3,4}$ However, the weak bonding strength between the $\mathrm{BN}$ support and $\mathrm{Pt}$ particles on Pt/BN is believed to be sufficient to fix Pt particles on the surface, particularly at low-temperature methanol oxidations. 


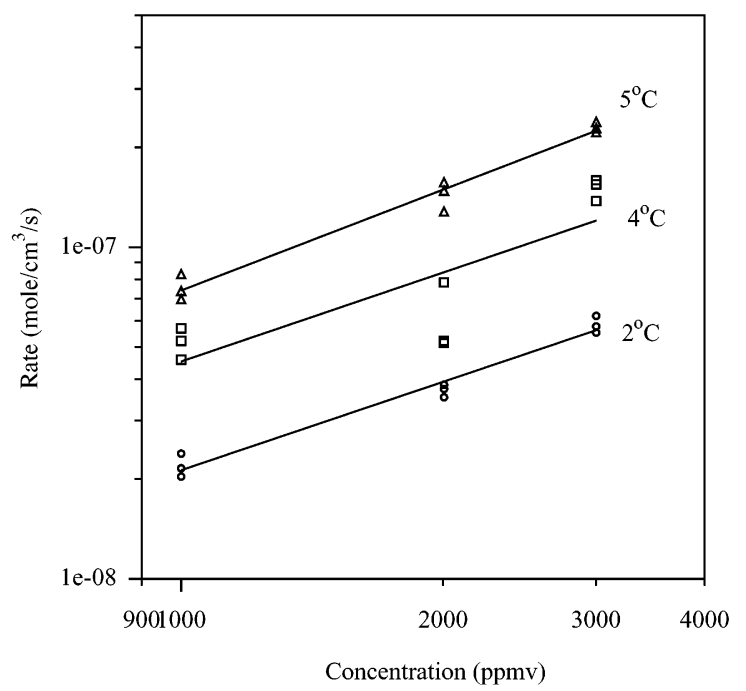

Figure 6. Reaction rates of various methanol concentrations in $20 \% \mathrm{O}_{2}$ on a $\mathrm{Pt} / \mathrm{BN}$ catalyst.

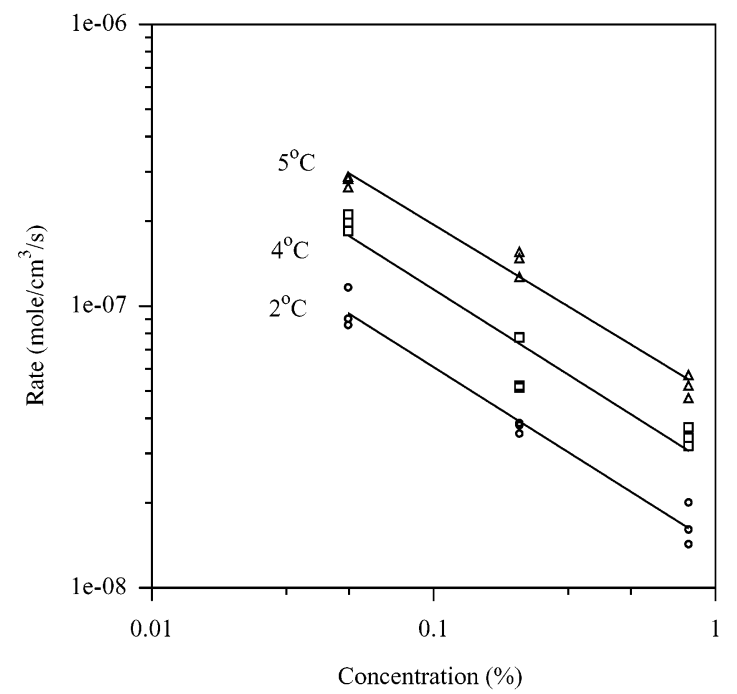

Figure 7. Reaction rates of various $\mathrm{O}_{2}$ concentrations in 2000 ppmv methanol on a Pt/BN catalyst.

Kinetic Analysis. The intrinsic kinetics are ensured by only using the low conversion $(<10 \%)$ data, in which diffusion limitations can be excluded. The apparent activation energy of methanol oxidation on Pt/BN is cal culated to be $267 \mathrm{~kJ} / \mathrm{mol}$ from an Arrhenius plot. The value of the apparent activation energy also suggests that the reaction is in the kinetic control region. The rate equation of methanol oxidation can be expressed by the concentrations of methanol and oxygen using a power law. Moreover, the exponents of methanol and oxygen can be estimated via regression analysis. Figures 6 and 7 display the rates versus concentrations of methanol and oxygen, respectively. The kinetic order of methanol is near 1 , while that of oxygen is -0.6 , based on the slopes calculated with the least-squares method. Equation 1 is the rate equation of methanol oxidation.

$$
-\mathrm{r}=\mathrm{k}^{\prime}\left[\mathrm{CH}_{3} \mathrm{OH}\right]\left[\mathrm{O}_{2}\right]^{-0.6}
$$

The kinetics of methanol oxidation were further analyzed using the Langmuir-Hinshel wood model. Our experimental results showed that only water and carbon dioxide were produced. Formal dehyde or dimethyl ether might be intermediate species, ${ }^{8}$ but neither was detected in the present experiment. Notably, only the adsorptions of methanol and oxygen were assumed on the Pt sites. Consequently, three elementary steps were proposed to describe the methanol oxidation on the Pt surface.

$$
\begin{gathered}
\mathrm{CH}_{3} \mathrm{OH}+\mathrm{i} \stackrel{\mathrm{k}}{\rightarrow} \mathrm{CH}_{3} \mathrm{OH}-\mathrm{i} \\
\mathrm{O}_{2}+2 \mathrm{i} \stackrel{\mathrm{k}_{2}}{\longrightarrow} 2 \mathrm{O}-\mathrm{i} \\
\mathrm{CH}_{3} \mathrm{OH}-\mathrm{i}+3 \mathrm{O}-\mathrm{i} \stackrel{\mathrm{k}_{3}}{\longrightarrow} \mathrm{CO}_{2}+2 \mathrm{H}_{2} \mathrm{O}+4 \mathrm{i}
\end{gathered}
$$

The rate-determining step (RDS) could be any one of the above three steps. Each RDS can derive an individual rate equation. According to the experimental results, the adsorption of methanol (eq 2) was found to be the most likely candidate for the RDS because the orders of methanol and oxygen were consistent with the experimental results. The rate equation is derived and presented in eq 5 where $C_{t}$ denotes the total number of

$$
-r=\frac{\mathrm{C}_{\mathrm{t}} \mathrm{k}\left[\mathrm{CH}_{3} \mathrm{OH}\right]}{1+\sqrt{\mathrm{K}_{2}\left[\mathrm{O}_{2}\right]}+\frac{\left[\mathrm{CO}_{2}\right]\left[\mathrm{H}_{2} \mathrm{O}\right]^{2}}{\mathrm{~K}_{3}\left[\sqrt{\mathrm{K}_{2}\left[\mathrm{O}_{2}\right.}\right]^{3}}}
$$

active sites that are constant for a given catalyst. $K_{2}$ and $\mathrm{K}_{3}$ are reaction equilibrium constants in eqs 3 and 4 , respectively. The denominator of eq 5 can be reduced to eq 6 because the concentrations of $\mathrm{H}_{2} \mathrm{O}$ and $\mathrm{CO}_{2}$ are extremely small (ppmv level) compared to those of $\mathrm{O}_{2}$ $(\sim 5-80 \%)$.

$$
-r=\frac{\mathrm{C}_{\mathrm{t}} \mathrm{k}\left[\mathrm{CH}_{3} \mathrm{OH}\right]}{1+\sqrt{\mathrm{K}_{2}\left[\mathrm{O}_{2}\right]}}
$$

The numerical value of $\mathrm{K}_{2}\left[\mathrm{O}_{2}\right]$ would exceed 1 because the dissociation adsorption $\left(\mathrm{K}_{2}\right)$ is significant in Pt active sites, and the concentration of $\mathrm{O}_{2}$ is also high in the present experimental condition. Consequently, eq 6 can be further reduced to eq 7. Finally, the kinetic order of methanol is first order and oxygen becomes negative half order, both of which kinetic orders agree closely with the experimental results (eq 1 ).

$$
-\mathrm{r}=\mathrm{C}_{\mathrm{t}} \mathrm{k} \sqrt{\mathrm{K}_{2}}\left[\mathrm{CO}_{3} \mathrm{OH}\right]\left[\mathrm{O}_{2}\right]^{-0.5}
$$

The negative order of the oxygen concentration indicates that oxygen inhibits the reaction rate. The adoxygen may cover most of the Pt active sites under high oxygen concentration (10-80\%) in our experimental conditions. Therefore, few Pt active sites are available for the methanol adsorption. That is al so the reason the RDS is the adsorption of methanol (eq 2).

\section{Conclusion}

This study presented favorable findings regarding methanol combustion employing BN supported Pt catalysts. Notably, the light-off temperature of methanol vapor was as low as $20^{\circ} \mathrm{C}$. Moreover, oxidation conversion exceeded $95 \%$ at near $75^{\circ} \mathrm{C}$. The weaker bonding between $\mathrm{BN}$ and Pt particles allow the Pt particles to remain in a reduced state more easily. The reduced state of the Pt particles on Pt/BN causes a weaker $\mathrm{Pt}-\mathrm{O}$ bond 
on the surface of Pt particles, providing highly reactive oxygen and thus promoting methanol oxidation. BN exhibits superior properties, including chemical inertness, thermal stability, thermal conductivity, and minimum metal-support interaction. Accordingly, BN is a promising support for a deep-oxidation catalyst.

\section{Acknowledgment}

The authors thank the National Science Council of the Republic of China and China Petroleum Corp. for financially supporting this research under Contract $\mathrm{N}$ os. NSC 89-CPC-7-002-014 and NSC 89-2214-E-002-065.

\section{Literature Cited}

(1) Spivey, J . J . Complete Catalytic Oxidation of Volatile Organics. Ind. Eng. Chem. Res. 1987, 26, 2165.

(2) Alkoy, S.; Toy, C.; Gonul, T.; Tekin, A. Crystallization Behavior and Characterization of Turbostratic Boron Nitride. J . Eur. Ceram. Soc. 1997, 17, 1415.
(3) Wu, J . C. S.; Lin, Z.-A.; Pan, J .-W.; Rei, M.-H. A novel boron nitride supported Pt catalyst for VOC incineration. Appl. Catal. A 2001, 219, 117.

(4) Lin, C.-A.; Wu, J . C. S.; Pan, J --W.; Yeh, C.-T. Characterization of Boron-Nitride-Supported Pt Catalysts for the Deep Oxidation of Benzene. J. Catal. 2002, 210, 39.

(5) Volter, J .; Lietz, G.; Spindler, H.; Lieske, H. Role of Metallic and Oxidic Platinum in the Catalytic Combustion of $\mathrm{n}$-Heptane. J . Catal. 1987, 104, 375.

(6) Aryafar, M.; Zaera, F. Kinetic study of the catalytic oxidation of alkanes over nickel, palladium and platinum foils. Catal. Lett. 1997, 48, 173.

(7) Hinz, A.; Larsson, P.-O.; Skårman, B.; Andersson, A. Platinum on alumina, titania, and magnesia supports for the combustion of methanol in a waste gas with trace amount of ammonia. Appl. Catal. B 2001, 34, 161.

(8) Yao, Y.-F. Y. Method of Treating Exhaust Gases From a Methanol Fueled Internal Combustion Engine. U.S. Patent 4,304,761, 1981.

Received for review November 4, 2002 Revised manuscript received April 16, 2003 Accepted May 6, 2003

IE020880L 